\title{
Estimate the useful life for a heating, ventilation, and air conditioning system on a high-speed train using failure models
}

\author{
Marcantonio Catelani ${ }^{1}$, Lorenzo Ciani ${ }^{1}$, Giulia Guidi ${ }^{1}$, Gabriele Patrizi ${ }^{1}$, Diego Galar ${ }^{2}$ \\ ${ }^{1}$ Department of information engineering, University of Florence via di S. Marta 3, 50139, Florence (Italy) \\ ${ }^{2}$ Luleå University of Technology, Lulea, Sweden
}

\begin{abstract}
Heating, ventilation, and air conditioning (HVAC) is a widely used system used to guarantee an acceptable level of occupancy comfort, to maintain good indoor air quality, and to minimize system costs and energy requirements. If failure data coming from company database are not available, then a reliability prediction based on failure rate model and handbook data must be carried out. Performing a reliability prediction provides an awareness of potential equipment degradation during the equipment life cycle. Otherwise, if field data regarding the component failures are available, then classical reliability assessment techniques such as Fault Tree Analysis and Reliability Block Diagram should be carried out. Reliability prediction of mechanical components is a challenging task that must be carefully assessed during the design of a system. For these reasons, this paper deals with the reliability assessment of an HVAC using both failure rate model for mechanical components and field data. The reliability obtained using the field data is compared to the one achieved using the failure rate models in order to assess a model which includes all the mechanical parts. The study highlights how it is fundamental to analyze the reliability of complex system integrating both field data and mathematical model.
\end{abstract}

Section: RESEARCH PAPER

Keywords: Reliability; Diagnostic; Railway engineering; failure rate; HVAC; useful life

Citation: Marcantonio Catelani, Lorenzo Ciani, Giulia Guidi, Gabriele Patrizi, Diego Galar, Estimate the useful life for a heating, ventilation, and air conditioning system on a high-speed train using failure models, Acta IMEKO, vol. 10, no. 3, article 10, September 2021, identifier: IMEKO-ACTA-10 (2021)-0310

Section Editor: Lorenzo Ciani, University of Florence, Italy

Received January 29, 2021; In final form August 2, 2021; Published September 2021

Copyright: This is an open-access article distributed under the terms of the Creative Commons Attribution 3.0 License, which permits unrestricted use, distribution, and reproduction in any medium, provided the original author and source are credited.

Corresponding author: Giulia Guidi, e-mail: giulia.guidi@unifi.it

\section{INTRODUCTION}

All devices are constituted from materials that will tend to degrade with time. The materials degradation will continue until some critical device parameter can no longer meet the required specification for proper device functionality [1]-[8]. For this reason, as well as the growing complexity of equipment and the rapidly increasing cost incurred by loss of operation and for maintenance, the interest in reliability is growing in many industrial fields.

Generally reliability could be assessed through different methods, such as Reliability prediction, Fault Tree Analysis, Reliability Block Diagram etc (see for instance [9]-[12]). Fault tree analysis (FTA) [13], [14] is an analytical and deductive (topdown) method. It is an organized graphical representation of the conditions or other factors causing or contributing to the occurrence of a defined outcome, referred to as the "top event". While, Reliability Block Diagram (RBD) [15] is a functional diagram of all the components making up the system that shows how component reliability contributes to failure or success of the whole system.

These above-mentioned techniques need input data to be performed but sometimes data are not available, and they need to be predicted. An accurate reliability prediction should be performed in the early stages of a development program to support the design process [16]-[21]. A reliability prediction of electronic components could be assessed following the guidelines of several handbooks, while the prediction of mechanical components is more challenging because of the following reasons [16], [22]:

- Individual mechanical components such as valves and gearboxes often perform more than one function and 
failure data for specific applications of nonstandard components are seldom available.

- Failure rates of mechanical components are not usually described by a constant failure rate distribution because of wear, fatigue and other stress-related failure mechanisms resulting in equipment degradation. Data gathering is complicated when the constant failure rate distribution cannot be assumed and individual times to failure must be recorded in addition to total operating hours and total failures.

- Mechanical equipment reliability is more sensitive to loading, operating mode and utilization rate than electronic equipment reliability. Failure rate data based on operating time alone are usually inadequate for a reliability prediction of mechanical equipment

- Definition of failure for mechanical equipment depends upon its application. Lack of such information in a failure rate data bank limits its usefulness.

The above listed problems demonstrates the need for reliability prediction models that do not rely solely on existing failure rate data banks [23], [24].

Trying to solve these needs, this paper aims to introduce a reliability assessment procedure which integrates failure rate models and field data to optimize the reliability analysis of a railway heating, ventilation and air conditioning (HVAC) system. The paper uses both FTA and RBD techniques to estimate the system reliability based on realistic failure rate models for mechanical components.

The rest of the paper is organized as follow: section 2 illustrates the aim of an HVAC and it presents the high-level taxonomy of the system under test; section 3 presents the failure rate prediction of three mechanical components (compressor, heat exchanger and blower) using failure models; section 4 shows the results of the reliability assessment carried out using FTA and RBD techniques and finally section 5 compares the results achieved with the different techniques.

\section{HVAC FOR HIGH-SPEED TRAIN}

Underground transport and rail systems become more and more frequent as they allow rapid transit times while transporting a large number of users [25]. Consequently, RAMS (reliability, availability, maintainability and safety) analysis has become a fundamental tool during the design of railway systems [25]-[27]. The network of high-speed trains and also standard rails are more and more transferred to underground tunnels in order to mitigate the environmental impact.

Both applications need ventilation rates. In Metros the influx of a large number of people and the presence of moving trains generate a reduction of oxygen and an increase in heat and pollutant. Mechanical ventilation is then required to achieve the necessary air exchange and grant users of the underground train systems comfortable conditions.

Ventilation systems have a second and even more important purpose. That is to guarantee safety in case of fire emergency. In order to create a safe and clean environment for escaping mechanical ventilation both in tunnels and in the stations is activated. In rails the ventilation of tunnels is mainly dedicated to fire emergencies where it is vital to keep under control the smoke propagation and create safe areas and clear environment for the users.

Furthermore, efficient temperature regulation is becoming a necessity to face overcrowded carriages [28]-[30]. HVAC is the

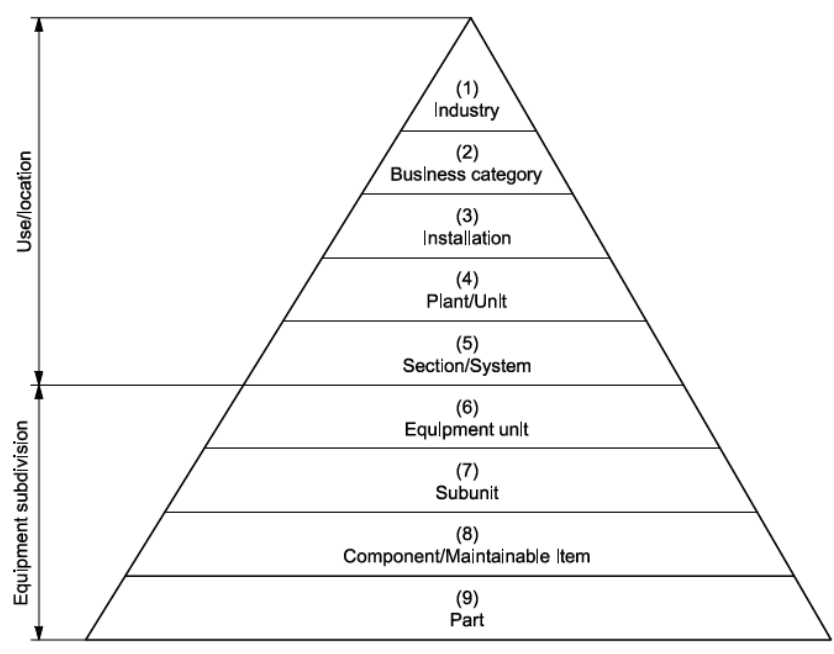

Figure 1. Taxonomy classification with taxonomic levels (SOURCE ISO 14224 - 2016 [34]).

best way of regulating temperature and air quality on crowded trains [31]. One of the most important guarantees that rail manufacturers should look for during the design of an air conditioning systems is reliability under the actual operating conditions [28], [32].

During the design of an HVAC system it is necessary to achieve information about the HVAC equipment and their uses[33]. The taxonomy is a systematic classification of items into generic groups based on factors possibly common to several of the items (location, use, equipment subdivision, etc.).

Referring to Figure 1, levels 1 to 5 represent a high-level categorization that relates to industries and plant application regardless of the equipment units (see level 6) involved. This is because an equipment unit (e.g., air conditioning unit) can be used in many different industries and plant configurations and, for analysing the failure/reliability/maintainability of similar equipment, it is necessary to have information about the operating context. Taxonomic information on these levels (1 to 5) shall be included in the database for each equipment unit as "use/location data". Levels 6 to 9 are related to the equipment unit (inventory) with the subdivision in lower indenture levels corresponding to a parent-child relationship.

The taxonomy of the system under test, from level 1 to level 5 is reported in Table 1 . The levels from 6 to 9 are very structured and include the level of the components divided also in the part sections.

\section{FAILURE RATE MODELS}

Predicting the life of a mechanical element is not easy, it includes mathematical equations to estimate the design life of mechanical components [16]. These reliability equations consider the design parameters, environmental extremes and operational stresses to predict the reliability parameters. The total failure rate of the

Table 1. Taxonomy of the system from level 1 to level 5.

\begin{tabular}{ll}
\hline Taxonomy level & Description \\
\hline Level 1 - Industry & Railway \\
Level 2 - Business Category & High Speed \\
Level 3 - Installation & S121 \\
Level 4 - Unit & Front car \\
Level 5 - System & HVAC system \\
\hline
\end{tabular}


component is the sum of the failure rates for the parts for a particular time period in question. The equations rely on a base failure rate derived from laboratory test data where the exact stress levels are known. More information about the failure rate data used in this work could be found in [19].

The most critical components of an Heating, Ventilation and Air Conditioning (HVAC) system are the compressor, the heat exchanger and the blower[25], [35]. In order to improve the failure rate of these items, the relative failure models have been analysed in the following sections.

\subsection{Compressor model}

A compressor system is made up of one or more stages. The compressor compresses the gas, increasing its temperature and pressure [16], [36]. The total compressor may be comprised of elements or groups of elements in series to form a multistage compressor based on the change in temperature and pressure across each stage.

Every compressor to be analyzed will be characterized by a unique design and it will be comprised of many different components. According to [16] and to the compressor datasheet, the designed HVAC compressor is a reciprocating type compressor. The following equation has been obtained in order to estimate the failure rate of the actual compressor used in the considered HVAC design.

$$
\lambda_{\mathrm{C}}=\left(\lambda_{\mathrm{FD}} \cdot C_{\mathrm{SF}}\right)+\lambda_{\mathrm{CA}}+\lambda_{\mathrm{BE}}+\lambda_{\mathrm{VA}}+\lambda_{\mathrm{SE}}+\lambda_{\mathrm{SH}},
$$

where

- $\lambda_{\mathrm{C}}$ is the total failure rate of compressor

- $\quad \lambda_{\mathrm{FD}}$ is failure rate of fluid driver

- $C_{\mathrm{SF}}$ is the compressor service multiplying factor

- $\lambda_{\mathrm{CA}}$ is the failure rate of the compressor casing

- $\lambda_{\mathrm{BE}}$ is the total failure rate of compressor shaft bearings

- $\lambda_{\mathrm{VA}}$ is the total failure rate of control valve assemblies

- $\lambda_{\mathrm{SE}}$ is the total failure rate of compressor seals

- $\lambda_{\mathrm{SH}}$ is the failure rate of compressor shaft.

Different compressor configurations such as piston, rotary screw and centrifugal have different parts within the total compressor and it is important to obtain a parts list for the compressor prior to estimating its reliability. The failure rate for each part comprising the compressor must be determined before the entire compressor assembly failure rate, $\lambda_{C}$, can be determined. Failure rates for each part will depend on expected operational and environmental factors that exist during compressor operation.

The total failure rate of compressor shaft bearings is:

$$
\lambda_{\mathrm{BE}}=\lambda_{\mathrm{BE}, \mathrm{B}} \cdot C_{\mathrm{R}} \cdot C_{\mathrm{V}} \cdot C_{\mathrm{CW}} \cdot C_{\mathrm{t}} \cdot C_{\mathrm{SF}} \cdot C_{\mathrm{C}},
$$

where

- $\quad \lambda_{\mathrm{BE}}$ is the total failure rate of bearing

- $\lambda_{\mathrm{BE}, \mathrm{B}}$ is base failure rate

- $C_{\mathrm{R}}$ is life adjustment factor for reliability

- $C_{\mathrm{V}}$ is multiplying factor for lubricant

- $C_{\mathrm{CW}}$ is multiplying factor for water contaminant level

- $C_{\mathrm{t}}$ is multiplying factor for operating temperature

- $C_{\mathrm{SF}}$ is multiplying factor for operating service conditions

- $C_{\mathrm{C}}$ is multiplying factor for lubrication contamination level.
The total failure rate of control valve assemblies is given by:

$\lambda_{\mathrm{VA}}=\lambda_{\mathrm{PO}}+\lambda_{\mathrm{SE}}+\lambda_{\mathrm{SP}}+\lambda_{\mathrm{SO}}+\lambda_{\mathrm{HO}}$,

where

- $\quad \lambda_{\mathrm{VA}}$ is the total failure rate of total valve assemblies

- $\lambda_{\mathrm{PO}}$ is the failure rate of poppet assembly

- $\lambda_{\mathrm{SE}}$ is the failure rate of the seals

- $\quad \lambda_{\mathrm{SP}}$ is the failure rate of spring(s)

- $\lambda_{\mathrm{SO}}$ is the failure rate of solenoid

- $\quad \lambda_{\mathrm{HO}}$ is the failure rate of valve housing

Consequently, using the failure data illustrated in [19] it is possible to solve equation (2)-(3). Then, the compressor failure rate could be estimated integrating these results into equation (1), as follow:

$$
\lambda_{\mathrm{C}}=1.56 \cdot 10^{-5} \text { failure } / \mathrm{h}
$$

Usually, failure rates of components implemented in railway applications are expressed in failure $/ \mathrm{km}$ or for sake of simplicity FPMK (Failure Per Million Kilometers).

Moreover, the duty cycle of the compressor must be taken into account in order to obtain a more accurate evaluation. Consequently, considering an approximate annual distance for high-speed train of half a million kilometers and a duty cycle of $30 \%$, the failure rate of the compressor becomes:

$$
\lambda_{\text {Compressor }}=8.22 \cdot 10^{-2} \mathrm{FPMK} \text {. }
$$

The failure rate achieved above must be compared with the failure rate provided by the manufacturer of the component (MERAK) which is obtained integrating field data and internal company tests.

$$
\lambda_{\text {Compressor,merak }}=7.79 \cdot 10^{-2} \mathrm{FPMK} \text {. }
$$

Comparing equations (5) and (6) it is possible to note that the failure rate obtained using the compressor model provides a value slightly higher than the one provided by the compressor manufacturer. The several variables considered by the failure model in equation (1) produce the different results since the Merak value is based mainly on field data.

Figure 2 shows the reliability curves relative to the failure rates of equations (5) and (6).

The blue line represents the reliability calculated with the manufacturer "MERAK" failure rate while the red one the reliability calculated using the failure model of the compressor. The curve obtained using the model decreases faster because its failure rate is higher than the MERAK failure rate. Anyway, the difference of the two curves is limited, at the beginning the

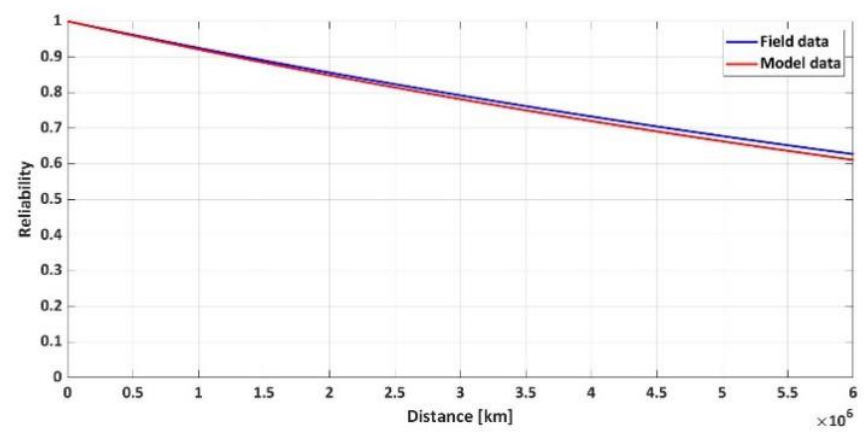

Figure 2. Reliability curves of the compressor assembly calculated through Merak data and compressor model given by equation (1). 
curves are approximately equal then they decrease with different exponential decay rates.

\subsection{Heat exchanger model}

Heat exchangers are essential part of any kind of HVAC system nowadays. The main function of a heat recovery system is to increase the energy efficiency by reducing energy consumption and also by reducing the cost of operating by transferring heat between two gases or fluids, thus reducing the energy consumptions. In heat exchangers, as the name suggests, there is a transfer of energy from one fluid to another. Both these fluids are physically separated and there is no direct contact between the fluids. There are different types of heat exchangers such as shell and tube, $\mathrm{U}$ tube, shell and coil, helical, plate etc. The transfer of heat can be between steam and water, water and steam, refrigerant and water, refrigerant and air, water and water.

The HVAC system's compressor generates heat by compressing refrigerant. This heat can be captured and used for heating domestic water. For this purpose, a heat exchanger is placed in between the compressor and the condenser. The water that is to be heated is circulated though this heat exchanger with the help of a pump whenever the HVAC system is on.

The heat exchanger included in the system under test is composed by a tube and an expansion valve. The failure rate of a fluid conductor is extremely sensitive to the operating environment of the system in which it is installed as compared to the design of the pipe. Each application must be evaluated individually because of the many installation, usage and maintenance variables that affect the failure rate. The failure of a piping assembly depends primarily on the connection joints and it can be estimated with the following equation [16]:

$$
\lambda_{\mathrm{P}}=\lambda_{\mathrm{P}, \mathrm{B}} \cdot C_{\mathrm{E}}=2.2 \cdot 10^{-6} \text { failure } / \mathrm{h}
$$

where

- $\quad \lambda_{\mathrm{P}}$ is the failure rate of pipe assembly

- $\lambda_{\mathrm{P}, \mathrm{B}}$ is the base failure rate of pipe assembly, which is $1.57 \cdot 10^{-6}$ failure $/ \mathrm{h}$

- $\quad C_{\mathrm{E}}$ is the environmental factor equal to 1.4 in case of a railway application.

For the expansion valve the failure rate is provided by [16] and it is $\lambda_{\mathrm{VA}}=4.5 \cdot 10^{-6}$ failure $/ \mathrm{h}$. Therefore, the whole failure rate of the heat exchanger is given by the sum of the failure rate of the pipe and the failure rate of the valve, each one weighted on its own duty cycle. In particular, the duty cycle of the pipe is $80 \%$ while the duty cycle of the valve is $30 \%$. Consequently, the failure rate of the heat exchanger is given by:

$$
\lambda_{\text {heat exchanger }}=3.11 \cdot 10^{-6} \text { failure } / \mathrm{h} \text {. }
$$

Quite the same as the compressor, also the failure rate of the heat exchanger must be converted from failure/h into FPMK. The heat exchanger failure rate in case of railway application is the following:

$$
\lambda_{\text {heat exchanger }}=5.4 \cdot 10^{-2} \mathrm{FPMK} \text {. }
$$

Also in this case, the failure rate based on field data has been provided by the component manufacturer MERAK and it is equal to:

$$
\lambda_{\text {heat exchanger,merak }}=4.124 \cdot 10^{-2} \mathrm{FPMK} \text {. }
$$

Figure 3 shows the two different reliability curves, the blue one is related to MERAK data while the red one is related to the model results achieved in equation (9). The model line results a pessimistic estimation also for this component.

The difference between the two reliability trends is extremely low. This is mainly due to the fact that for a simpler element like the heat exchanger, the manufacturer MERAK and model lead to a similar result.

\subsection{Blower model}

One of the most common downfalls of installed HVAC systems is their inability to distribute the correct amount of air to where it's needed most. When systems are restrictive, or blowers aren't powerful enough, the air simply doesn't make it to where it needs to go.

A blower is composed by:

- an AC motor;

- two bearings;

- a fan.

The failure rate of a motor is affected by such factors as insulation deterioration, wear of sliding parts, bearing deterioration, torque, load size and type, overhung loads, thrust loads and rotational speed. The failure rate model developed is based on a fractional or integral horsepower AC type motor. The reliability of an electric motor is dependent upon the reliability of its parts, which may include bearings, electrical windings, armature/shaft, housing, gears and brushes. Failure mechanisms resulting in part degradation and failure rate distribution (as a function of time) are considered to be independent in each failure rate model. The total motor system failure rate is the sum of the failure rate of each of the parts in the motor:

$$
\lambda_{\text {motor }}=\lambda_{\mathrm{M}, \mathrm{B}} \cdot C_{\mathrm{SF}}+\lambda_{\mathrm{WI}}+\lambda_{\mathrm{ST}}+\lambda_{\mathrm{AS}}+\lambda_{\mathrm{BE}}+\lambda_{\mathrm{GR}}+\lambda_{\mathrm{C}},
$$

where

- $\lambda_{\text {motor }}$ is the total failure rate for the motor system

- $\lambda_{\mathrm{M}, \mathrm{B}}$ is the base failure rate of motor

- $C_{\mathrm{SF}}$ is the motor load service factor

- $\lambda_{\mathrm{WI}}$ is the failure rate of electric motor windings

- $\lambda_{\mathrm{ST}}$ is the failure rate of the stator housing

- $\quad \lambda_{\mathrm{AS}}$ is the failure rate of the armature shaft

- $\lambda_{\mathrm{BE}}$ is the failure rate of the bearing evaluated using equation (2) and the suitable factors

- $\quad \lambda_{\mathrm{GR}}$ is the failure rate of gears

- $\lambda_{\mathrm{C}}$ is the failure rate of capacitor.

The bearings failure rate could be estimated following the guidelines in section 3.1 .

The fans are modelled in according to MIL-STD-217F [37] by:

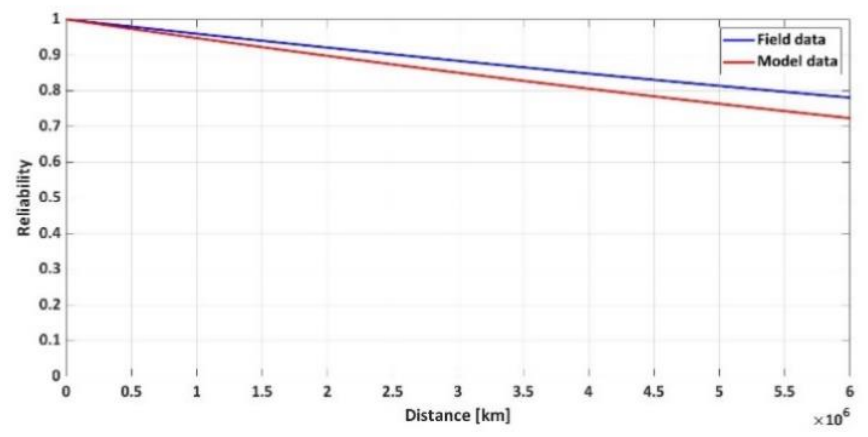

Figure 3. Reliability curves of the heat exchanger assembly calculated through Merak data and heat exchanger model according to equation (9). 


$$
\lambda_{\mathrm{Fan}}=\left[\frac{t^{2}}{\alpha_{B}^{3}}+\frac{1}{\alpha_{W}}\right] \text { failure } / \mathrm{h}
$$

where

- $\mathrm{t}$ is the motor operating time period

- $\alpha_{\mathrm{B}}$ the Weibull characteristics life for motor bearing

- $\alpha_{\mathrm{W}}$ the Weibull characteristics life for motor windings

Finally, the whole blower failure rate is given by the sum of the failure rates of its components, so:

$$
\begin{aligned}
\lambda_{\text {Blower }} & =\lambda_{\text {motor }}+2 \cdot \lambda_{\text {bearing }}+\lambda_{\text {Fan }} \\
& =1.328 \cdot 10^{-5} \text { failure } / \mathrm{h} .
\end{aligned}
$$

Then considering the duty cycle of $100 \%$ and the required conversion from failure/ $h$ into FPMK, the blower failure rate become:

$$
\lambda_{\text {Blower }}=2.33 \cdot 10^{-1} \mathrm{FPMK}
$$

The failure rate achieved analyzing field data has been provided by the component manufacturer MERAK, and it is illustrated in the following:

$$
\lambda_{\text {Blower,merak }}=7.97 \cdot 10^{-2} \mathrm{FPMK} \text {. }
$$

Figure 4 shows the two reliability curves, the blue one is related to the MERAK data and the red one is related to the model data.

Like for the other components, the reliability calculated through the models provides a pessimistic reliability trend respect the reliability calculated with the field data provided by MERAK. This time, the differences between field data and model data is quite remarkable. This could be due to the harsh operating condition considered by the failure rate model in [16].

\section{RELIABILITY ANALYSIS}

When the data (coming from tests or from the manufacturer) are available, techniques such as FTA or RBD could be used to estimate the useful life of the system.

\subsection{Fault tree analysis}

Fault tree diagrams consist of gates and events connected with lines. The AND and OR gates are the two most commonly used gates in a fault tree. To illustrate the use of these gates, consider two events (called "input events") that can lead to another event (called the "output event")[14], [35]. If the occurrence of either input event causes the output event to occur, then these input events are connected using an OR gate. Alternatively, if both

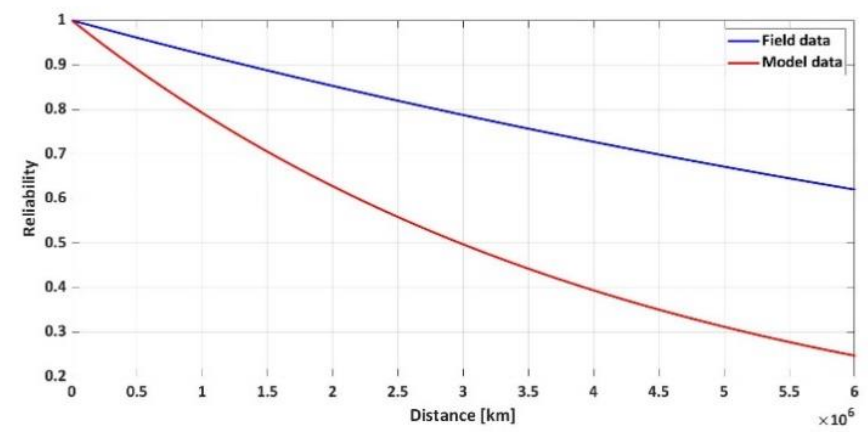

Figure 4. Reliability curves of the blower assembly calculated through Merak data and blower model as in equation (14). input events must occur in order to the occurrence of the output event, then they are connected by an AND gate.

Fault tree analysis gates can also be combined to create more complex representations. In case of the HVAC system under analysis, the top event is "HVAC failure" and it's caused by four different events, as illustrate in Figure 5:

- "Possible fire", when some events could involve a risk of fire in the railway cabin.

- "Loss of emergency ventilation", when the emergency ventilation doesn't work.

- "Loss of functions caused by a single event", when a single event causes a direct loss of all the cooling, heating, ventilation function

- "Indirect loss of cooling heating and ventilation", when some events cause independently a loss of cooling, heating and ventilation functions.

The top event "HVAC failure" is linked to the abovedescribed input events trough an OR gate, that means if at least one of the four input events happens the whole system fails. Every one of the input events in Figure 5 is in turn caused by an extremely complex combinations of several events.

The complete FTA diagram is very large and structured, and it is not possible to show it entirely. So, for the sake of simplicity, Figure 5 shows only an extract of these FTA.

The reliability trend considering the FTA configuration is shown in Figure 6. The curve is a decreasing exponential, it starts from a unitary reliability and it tends to zero. The analysis is simulated starting from $0 \mathrm{~km}$ up to $6 \cdot 10^{6} \mathrm{~km}$. According to an annual forecast distance traversed of about $487 \cdot 10^{3} \mathrm{~km}$, the simulation in term of time is over 12 years.

At distance $0.5 \cdot 10^{6} \mathrm{~km}$ (approximately 1 year) the reliability is around the $80 \%$, while after $1 \cdot 10^{6} \mathrm{~km}$ (approximately 2 years) is decrease approximately to the $60 \%$ and then it tends to zero at $5 \cdot 10^{6} \mathrm{~km}$ (approximately 10 years). These results are justified by two reasons:

- The mechanical nature of the whole system, that contributes to a fast decrease of the reliability.

- The OR gate that lead to the top event, which is the worst-case scenario between the several ones considered during the design.

\subsection{Reliability block diagram}

An overall system reliability prediction can be made by looking at the reliabilities of the components that make up the whole system or product. In order to construct a reliability block diagram, the reliability-wise configuration of the components must be determined. Consequently, the analysis method used for computing the reliability of a system will also depend on the reliability-wise configuration of the components/subsystems.

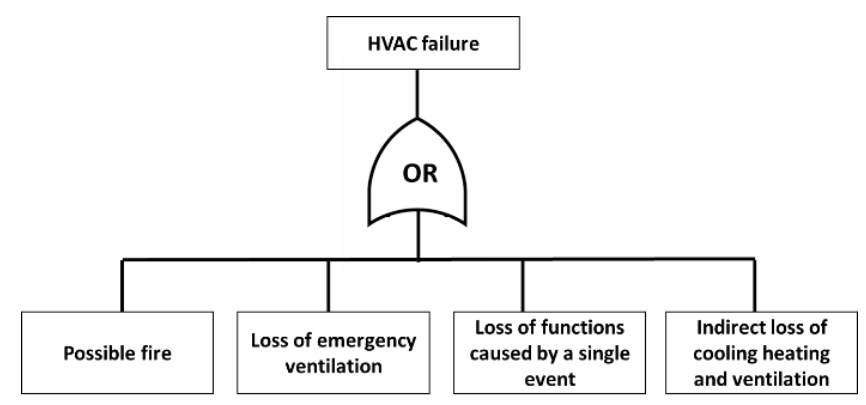

Figure 5. Extract of the FTA Diagram for the HVAC system under analysis. 


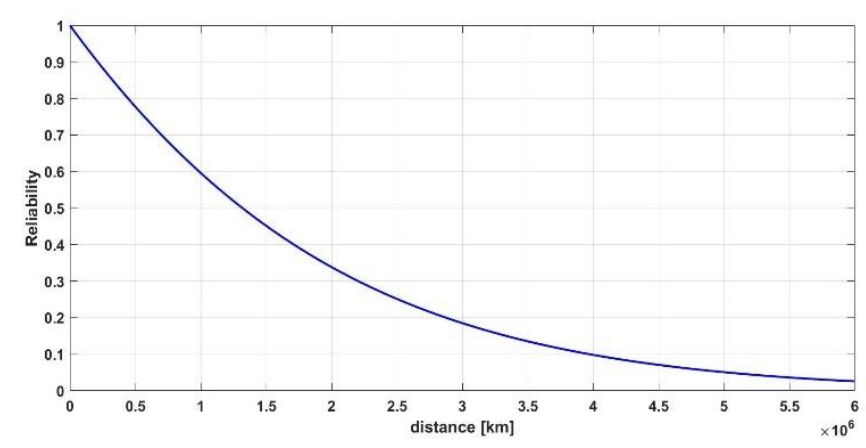

Figure 6. Reliability trend of the FTA.

That configuration can be as simple as units arranged in a pure series or parallel configuration. There can also be systems of combined series/parallel configurations or complex systems that cannot be decomposed into groups of series and parallel configurations.

The HVAC system under analysis could be described using a series of three main blocks (see Figure 7):

- Cooling system

- Heating system

- Ventilation system.

Therefore, supposing the exponential distribution for all the items [18], [38], [39], the reliability equation of the whole system is:

$$
R_{\text {SYS }}(t)=\mathrm{e}^{-\left(\lambda_{\text {cooling }}+\lambda_{\text {heating }}+\lambda_{\text {ventilation }}\right) \cdot t} .
$$

Figure 8 shows a comparison between cooling, heating and ventilation reliability curves. The figure also shows the whole system reliability trend calculated with equation (16), which is illustrated using a dashed black line.

The red line represents the heating system, the blue line the ventilation system and the green line the cooling system. The worst system, in reliability terms, is the cooling system, because it contains a lot of series elements and most of them are mechanical items.

The three systems are connected in a series configuration, where the component with the least reliability has the biggest effect on the system's reliability. As a result, the reliability of a series system is always less than the reliability of the least reliable component.

That's why the black line, representing the whole system reliability is lower than the cooling curve (the least reliable).

\subsection{Comparison between FTA and RBD results}

Table 2 shows the comparison of the reliability trends between the two proposed methods: Reliability Block Diagram and Fault Tree Analysis.

The two curves are very similar, but the RBD reliability is always higher than the FTA results (at every distance). The differences could be caused by:

- Different algorithm used by the software for the calculation of the reliability.

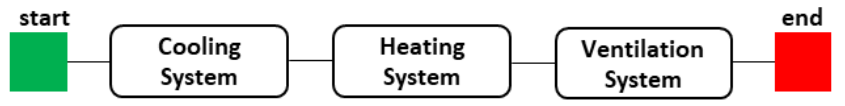

Figure 7. Reliability block diagram of the HVAC system.

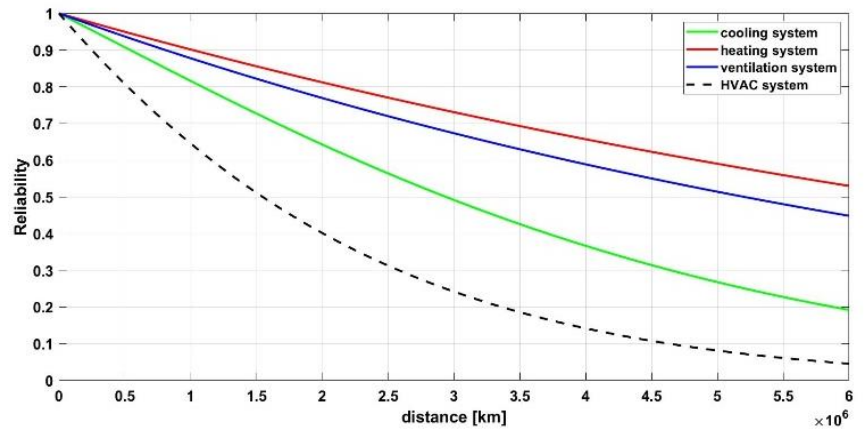

Figure 8. Reliability trends of cooling, heating and ventilation systems (continuous lines) compared with the HVAC system reliability (dashed line).

- The FTA analysis results are more complete and they consider all the possible path that lead to the top event, so it considers also the relationship between failures.

The first column of Table 2 reports the distance travelled by the train, the second the corresponding time, the third and the fourth the reliability values of the FTA and RBD respectively. The last one reports the absolute percentage difference of the two previous columns. All the values relative to the RBD are higher than the FTA, but their difference is lower than $6 \%$. Figure 9 shows the trend of the difference between the two curves, it illustrates that the maximum value is $6.5 \%$, so the difference is very low. At the beginning the difference is not remarkable, in particular before $1000000 \mathrm{~km}$ is lower than $4 \%$, then it increases, and the peak is between $1500000 \mathrm{~km}$ and $2500000 \mathrm{~km}$ where the difference is $6 \%$. After that, it decreases slowly and it reaches the value of $2 \%$ at $6000000 \mathrm{~km}$.

Therefore, the two methods provide comparable results, and both the outcomes are valid.

\section{COMPARISON BETWEEN FIELD DATA AND MODEL DATA}

A comparison between the failure estimation of the previous paragraphs and the failure data provided by the manufacturer of the HVAC has been carried out in order to investigate how the model-based failure rates affect the reliability trend of the whole system.

The model-based failure rates of compressor, blower and heat exchanger are used to calculate the whole HVAC reliability together with the failure rate estimation of the other components, which make up the system.

Table 2. Reliability data of OR type FTA and RBD

\begin{tabular}{ccccc}
\hline $\begin{array}{c}\text { Distance } \\
\mathbf{k m}\end{array}$ & time & $\boldsymbol{R}_{\mathrm{fta}}$ & $\boldsymbol{R}_{\mathrm{rbd}}$ & Difference \\
\hline $0.5 \cdot 10^{6}$ & 1 year & 0.78 & 0.80 & $3 \%$ \\
$1 \cdot 10^{6}$ & 2 years & 0.60 & 0.64 & $4 \%$ \\
$2 \cdot 10^{6}$ & 4 years & 0.34 & 0.40 & $6 \%$ \\
$3 \cdot 10^{6}$ & 6 years & 0.18 & 0.24 & $6 \%$ \\
$4 \cdot 10^{6}$ & 8 years & 0.1 & 0.14 & $4 \%$ \\
$5 \cdot 10^{6}$ & 10 years & 0.05 & 0.08 & $3 \%$ \\
$6 \cdot 10^{6}$ & 12 years & 0.03 & 0.05 & $2 \%$ \\
\hline
\end{tabular}




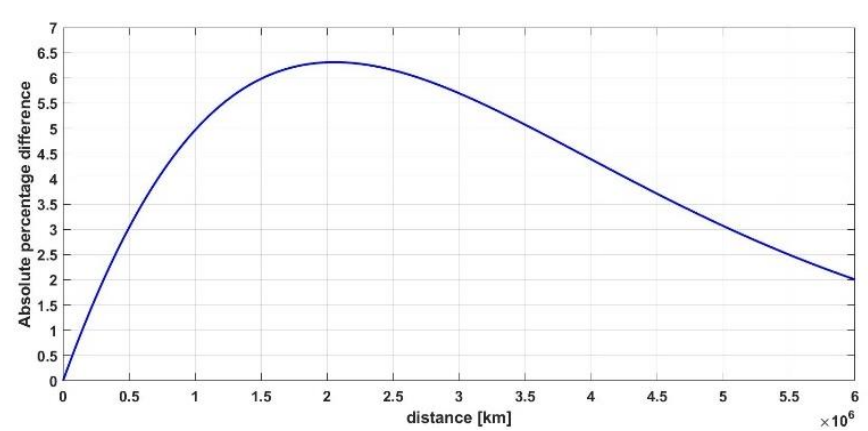

Figure 9. Absolute percentage difference between the two reliability trends achieved using RBD and FTA methods.

Figure 10 shows three reliability curves, the blue trend is related to the FTA reliability, the red one is calculated with the RBD analysis, while the green one is related to the failure rate of the components calculated using the failure models.

It's possible to note that the model-based failure rates contribute to reduce the reliability and have an important contribution to the whole system reliability.

The failure rate models provide a pessimistic reliability results for the three components analyzed before. Consequently, their reliability curves affect the whole system reliability, producing a trend lower than the ones calculated with the manufacturer data (in case of both FTA and RBD techniques.

\section{CONCLUSION}

The paper deals with a heating, ventilation and air conditioning system mounted on a high-speed train. The first part of the paper illustrates the taxonomy of the system under study. The architecture of an HVAC system includes several critical components, such as: a fan (blower), a heat exchanger and a compressor.

A detailed study on the failure rates of the HVAC most critical components is presented in this paper. Compressor, heat exchanger and blower show a model-based reliability lower than the reliability achieved using the field data provided by the manufacturer of the HVAC "MERAK". Then, the reliability of the complete HVAC system has been estimated using two wellknown techniques: Fault Tree Analysis and Reliability Block Diagram. FTA and RBD methods take the field data provided by MERAK as input to evaluate the system reliability over distance travelled by the train. The final analysis shows how the model failure rates affect the whole HVAC reliability comparing the results achieved using FTA and RBD with the one obtained using the failure rate models. The model-based failure rate provides a pessimistic result because it considers every possible

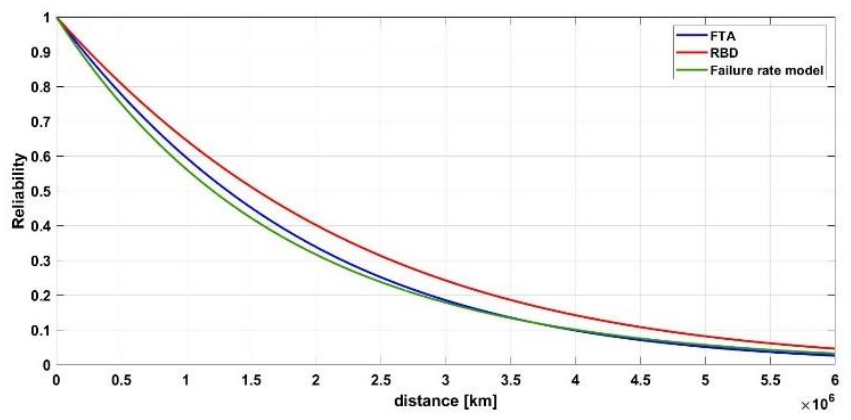

Figure 10. Reliability curves of the HVAC assembly calculated through Merak data (both FTA and RBD techniques) and model data. failure modes and failure mechanisms of each subitem that make up the component. Despite this. it could be not so realistic since it doesn't properly consider the real operating conditions of the system under test. Quite the opposite, the reliability evaluated using the field data takes into account the real context of the HVAC but some of the failure mechanisms might be not occur during the observed time interval. For these reasons. it is fundamental to analyze the reliability of such complex system integrating both techniques.

\section{REFERENCES}

[1] G. D’Emilia, A. Gaspari, E. Hohwieler, A. Laghmouchi, E. Uhlmann, Improvement of Defect Detectability in Machine Tools Using Sensor-based Condition Monitoring Applications, Procedia CIRP, vol. 67, 2018, pp. 325-331.

DOI: $10.1016 /$ j.procir.2017.12.221

[2] D. Capriglione, M. Carratu, A. Pietrosanto, P. Sommella, Online Fault Detection of Rear Stroke Suspension Sensor in Motorcycle, IEEE Trans. Instrum. Meas., vol. 68, no. 5, May 2019, pp. 13621372. DOI: $10.1109 /$ TIM.2019.2905945

[3] A. Paggi, G. L. Mariotti, R. Paggi, F. Leccese, General Reliability Assessment via the Physics-Based, in 2020 IEEE 7th International Workshop on Metrology for AeroSpace (MetroAeroSpace), Jun. 2020, pp. 510-515.

DOI: $10.1109 /$ MetroAeroSpace48742.2020.9160087

[4] G. D'Emilia, A. Gaspari, E. Natale, Measurements for Smart Manufacturing in an Industry 4.0 Scenario A Case-Study on A Mechatronic System, in 2018 Workshop on Metrology for Industry 4.0 and IoT, Apr. 2018, pp. 1-5. DOI: $10.1109 /$ METROI4.2018.8428341

[5] D. Capriglione, M. Carratù, A. Pietrosanto, P. Sommella, NARX ANN-based instrument fault detection in motorcycle, Measurement, vol. 117, Mar. 2018, pp. 304-311.

DOI: $10.1016 /$ i.measurement.2017.12.026

[6] U. Leturiondo, O. Salgado, D. Galar, Estimation of the Reliability of Rolling Element Bearings Using a Synthetic Failure Rate, 2016, pp. 99-112.

[7] A. Reatti, F. Corti, L. Pugi, Wireless Power Transfer for Static Railway Applications, in 2018 IEEE International Conference on Environment and Electrical Engineering and 2018 IEEE Industrial and Commercial Power Systems Europe (EEEIC / I\&CPS Europe), Jun. 2018, pp. 1-6.

DOI: $10.1109 /$ EEEIC.2018.8493757

[8] S. Giarnetti, E. De Francesco, R. De Francesco, F. Nanni, M. Cagnetti, F. Leccese, E. Petritoli, G. Schirripa Spagnolo, A New Approach to define reproducibility of Additive Layers manufactured components, in 2020 IEEE 7th International Workshop on Metrology for AeroSpace (MetroAeroSpace), Jun. 2020, pp. 529-533.

DOI: $10.1109 /$ MetroAeroSpace48742.2020.9160076

[9] E. Petritoli, F. Leccese, M. Botticelli, S. Pizzuti, F. Pieroni, A RAMS analysis for a precision scale-up configuration of the 'Smart Street' pilot site: an industry 4.0 case study, ACTA IMEKO 8 (2019) 2, pp. 3-11. DOI: $10.21014 /$ acta imeko.v8i2.614

[10] M. Khalil, C. Laurano, G. Leone, M. Zanoni, Outage severity analysis and RAM evaluation of Italian overhead transmission lines from a regional perspective, Acta IMEKO 5 (2016) 4, pp. 73 79 . DOI: $\underline{10.21014 / \text { acta imeko.v5i4.424 }}$

[11] P. Liu, X. Cheng, Y. Qin, Y. Zhang, Z. Xing, Reliability Analysis of Metro Door System Based on Fuzzy Reasoning Petri Net, in Lecture Notes in Electrical Engineering, vol. 288 LNEE, no. VOL. 2, 2014, pp. 283-291.

[12] L. Cristaldi, M. Khalil, M. Faifer, Markov process reliability model for photovoltaic module failures, ACTA IMEKO 6 (2017) 4, pp. 
121-130.

DOI: $\underline{10.21014 / \text { acta imeko.v6i4.428 }}$

[13] IEC 61025, Fault tree analysis (FTA). International Electrotechnical Commission, 2007.

[14] L. Ciani, G. Guidi, D. Galar, Reliability evaluation of an HVAC ventilation system with FTA and RBD analysis, 2020.

[15] IEC 61078, Reliability block diagram. International Electrotechnical Commission, 2016.

[16] NSWC, Handbook of Reliability Prediction Procedures for Mechanical Equipment, no. May. 2011.

[17] M. Catelani, L. Ciani, A. Bartolini, G. Guidi, G. Patrizi, Standby Redundancy for Reliability Improvement of Wireless Sensor Network, in 2019 IEEE 5th International forum on Research and Technology for Society and Industry (RTSI), Sep. 2019, pp. 364 369. DOI: $10.1109 /$ RTSI.2019.8895533

[18] M. Rausand, A. Hoyland, System Reliability Theory, Second. John Wiley \& Sons, Inc., 2004.

[19] M. Catelani, L. Ciani, G. Guidi, D. Galar, A Practical Solution for HVAC Life Estimation Using Failure Models, 2020.

[20] A. Paggi, G. L. Mariotti, R. Paggi, A. Calogero, F. Leccese, Prediction by means hazard rate occurrence is a deeply wrong approach, in 2017 IEEE International Workshop on Metrology for AeroSpace (MetroAeroSpace), June 2017, pp. 276-281. DOI: $10.1109 /$ MetroAeroSpace.2017.7999580

[21] M. Catelani, L. Ciani, M. Venzi, Component Reliability Importance assessment on complex systems using Credible Improvement Potential, Microelectron. Reliab., vol. 64, Sep. 2016, pp. 113-119. DOI: $10.1016 /$ j.microrel.2016.07.055

[22] B. S. Dhillon, Human Reliability and Error in Transportation Systems. Springer-Verlag, 2007.

[23] L. Ciani, G. Guidi, Application and analysis of methods for the evaluation of failure rate distribution parameters for avionics components, Measurement, vol. 139, June 2019, pp. 258-269. DOI: $10.1016 /$ i.measurement.2019.02.082

[24] J. G. McLeish, Enhancing MIL-HDBK-217 reliability predictions with physics of failure methods, 2010 Proceedings of the Annual Reliability and Maintainability Symposium (RAMS), Jan. 2010, pp. 1-6. DOI: $10.1109 /$ RAMS.2010.5448044

[25] M. Catelani, L. Ciani, G. Guidi, G. Patrizi, Maintainability improvement using allocation methods for railway systems, ACTA IMEKO 9 (2020) 1, pp. 10-17. DOI: $10.21014 /$ acta imeko.v9i1.733

[26] A. Massaro, E. Cannella, G. Dipierro, A. Galiano, G. D’andrea, and G. Malito, Maintenance and testing protocols in the railway industry, ACTA IMEKO 9 (2020) 4, pp. 4-12.

DOI: $\underline{10.21014 / \mathrm{acta} \text { imeko.v9i4.718 }}$

[27] T. Addabbo, A. Fort, C. Della Giovampaola, M. Mugnaini, A. Toccafondi, V. Vignoli, On the safety design of radar based railway level crossing surveillance systems, ACTA IMEKO 5 (2016) 4, pp. 64-72.

DOI: $10.21014 /$ acta imeko.v5i4.419

[28] A. Vedavarz, S. Kumar, M. I. Hussain, HVAC Handbook of Heating, Ventilation, and Air Conditioning for Design \& Implementation, Fourth. industrial press inc., 2013.

[29] S. C. Sugarman, HVAC fundamentals, Second. CRC Press: Taylor \& Francis Group, 2007.

[30] L. Tanghong, X. Gang, Test and Improvement of Ventilation Cooling System for High-Speed Train, in 2010 International Conference on Optoelectronics and Image Processing, vol. 2, Nov. 2010, pp. 493-497. DOI: $10.1109 /$ ICOIP.2010.55

[31] C. Luger, R. Rieberer, Multi-objective design optimization of a rail HVAC CO2 cycle, Int. J. Refrig., vol. 92, pp. 133-142, 2018. DOI: $\underline{10.1016 / \text { j.ijrefrig. } 2018.05 .033}$

[32] F. Porges, HVAC Engineer handbook, Eleventh. Elsevier Science \& Technology Books, 2001.

[33] L. Marjanovic-Halburd, I. Korolija, V. I. Hanby, Heating Ventilating and Air-Conditioning (HVAC) equipment taxonomy, in IIR 2008 - HVAC Energy Efficiency Best Practice Conference, 2008, no. February 2016.

[34] International Organization for Standardization, ISO 14224 Petroleum, petrochemical and natural gas industries - Collection and exchange of reliability and maintenance data for equipment. 2016.

[35] L. Ciani, G. Guidi, G. Patrizi, A Critical Comparison of Alternative Risk Priority Numbers in Failure Modes, Effects, and Criticality Analysis, IEEE Access, vol. 7, no. D, 2019, pp. 92398-92409, DOI: $10.1109 /$ ACCESS.2019.2928120

[36] I. Values, Compressor Selection: Semi-hermetic Reciprocating Compressors Technical Data: (4G-30.2Y) Dimensions and Connections, pp. 4-7, 2015.

[37] MIL-HDBK-217F, Military Handbook - Reliability Prediction of Electronic Equipment. US Department of Defense, Washington DC, 1991.

[38] A. Birolini, Reliability Engineering. Berlin, Heidelberg: Springer Berlin Heidelberg, 2017. DOI 10.1007/978-3-662-54209-5

[39] M. Lazzaroni, L. Cristaldi, L. Peretto, P. Rinaldi, M. Catelani, Reliability Analysis in the Design Phase, in: Reliability Engineering. Berlin, Heidelberg: Springer Berlin Heidelberg, 2011. DOI: $10.1007 / 978-3-642-20983-3 \quad 3$ 